\title{
The Mediating Role of Strategy Execution on the Relationship Between TMT Characteristics and Organizational Performance in a Regulatory Setting in Kenya
}

\author{
Joseph Odongo Oketch, James Mutuku Kilika, Godfrey Muigai Kinyua \\ Department of Business Administration, Kenyatta University, Nairobi, Kenya \\ Email address: \\ jseph.oketch@gmail.com (J. O. Oketch),jmkilika@gmail.com (J. M. Kilika), jefkinyua@gmail.com (G. M. Kinyua)
}

\section{To cite this article:}

Joseph Odongo Oketch, James Mutuku Kilika, Godfrey Muigai Kinyua. The Mediating Role of Strategy Execution on the Relationship Between TMT Characteristics and Organizational Performance in a Regulatory Setting in Kenya. Journal of Business and Economic Development. Vol. 6, No. 1, 2021, pp. 12-22. doi: 10.11648/j.jbed.20210601.12

Received: January 7, 2021; Accepted: February 1, 2021; Published: February 9, 2021

\begin{abstract}
There is consensus among strategic management scholars and practitioners that strategic management as a practice has a vital role in organizational performance. It has also been argued that the strategic management process can be divided into four broad stages namely, strategy formulation, strategy execution, strategy monitoring and strategy evaluation. Some strategic management scholars have asserted that the strategy execution process can make a sound strategic decision ineffective or a debatable strategic choice successful. The specific objective of the study was to establish the mediating effect of strategy execution on the relationship between top management team characteristics and organizational performance of independent regulatory agencies in Kenya. The study embraced descriptive cross-sectional research design. The target population of the study was all the twenty-three independent regulatory agencies currently existing in Kenya. The study adopted a census survey of all the top management team members in all the twenty-three independent regulatory agencies in order to capture the required information due to the uniqueness of each independent regulatory agency and the distinct roles played by each top management team member in their organizations. Structured questionnaire administered through drop and pick later method was used to gather primary data from the respondents. Descriptive statistics of the respondents was summarized into percentages, frequencies, means and standard deviations for interpretation. The mediation effect was tested using the Baron and Kenny model. The findings of the study showed that strategy execution partially mediates the relationship between TMT characteristics and Organizational Performance of the independent regulatory agencies in Kenya. The study recommends that independent regulatory agencies need to develop a reward system for their TMTs who excel in executing their organizational strategies so that they can be motivated, and to provide an opportunity for the managers to compete amongst themselves in order to achieve superior organizational performance. Lastly, the study recommends that the independent regulatory agencies should have stable funding mechanism to enable them execute their identified strategies in order to achieve and sustain superior organizational performance.
\end{abstract}

Keywords: Top Management Team Characteristics, Strategy Execution, Independent Regulatory Agencies, Organizational Performance

\section{Introduction}

Strategic management scholars and practitioners have defined strategy execution as the means through which organizations turn their strategies and plans into activities, projects or programs meant to realize their organizational objectives and goals [36]. Strategy execution in any organization is a critical stage of the strategic planning process as it addresses the details of how to carry out the identified strategic activities splendidly to stir the organization to projected superior organizational performance. Strategy execution entails breaking down the organization's strategic plan into executable work plans, identifying funding for the various activities, communicating the strategies within the organization's cycles and lastly instituting strategic controls [26]. Managers in the 
organization at different levels and employees are always involved in the strategy execution stage. This necessitates satisfactory engagement between the parties involved to ensure successful strategy execution. The strategy execution process therefore involves a critical look at organizational objectives, policies, resources, organization structure, organizational culture, management of conflict and managing resistance to change in order to propel the organization towards the projected organizational performance [28].

It has been argued that strategy execution should involve continuous environmental scanning to identify emerging strategic issues like strengths, weaknesses, opportunities and threats in order to all the time align the organization's strategies with the objectives and goals [44]. Strategy execution is therefore that critical process that translates the plans and strategies into action to realize the set objectives and propel the organizations towards attaining their goals. The organization's strategic plan is a blue print of how the business intends to reach its goals but will sit forgotten without strategy execution. Strategy execution therefore makes the organization's plans happen [11]. Strategy execution in any organization therefore requires team effort headed by the organization's top management team. Strategy execution should also always involve change management. It is hence vital for the entire organization to understand and embrace the part played by leadership in strategy execution in order to make the process yield desired organizational performance and avoid negative effects that may arise from resistance to change [28].

Previous researchers in strategic management have shown that $66 \%$ of organizational strategies are never executed [13]. Some of the researchers have argued that $95 \%$ of staff have no knowledge of their organizations' strategies [15] and that only $63 \%$ of commercial outcomes projected by organizations' strategies are realized [21]. The previous researchers have also shown that $70 \%$ to $90 \%$ of organizations fail to realize the forecasted achievements of executing their plans [16] and that the most rampant cause of failure in strategies is unsuccessful execution [39]. Other previous studies have also shown that staff skills, firm systems and processes, management style, organizational culture and structure while aligned to organizational activities have a significant positive effect on strategy execution that in the end yield superior organizational performance [20].

Top management teams (TMTs) in any organization are the high-ranking officials that include the head of the organizations and their direct reports. The titles of the TMTs however vary from one organization to another depending on the nature of business, scope of operation, organizational culture and ownership of the organizations among other factors. Some common titles for the TMTs are chairman/chairperson, president, chief executive officer, managing director, executive directors, and executive vice presidents among others. These positions are responsible for their entire organizations, divisions, departments or units within their organizations [29]. Top management teams apart from overseeing the daily operations of their organizations, departments, units or divisions, are responsible for translating the policies and guidelines formulated by their board of directors into goals, objectives, strategies, projects and programs meant to steer their organizations to sustained superior organizational performance. The top management teams are therefore mandated to make decisions that affect major processes and daily operations in their organizations, divisions, units or departments in order to project their organizations to sustained superior organizational performance [34].

Top management team characteristics refer to unique personal traits ascribed to members of the TMTs that are either instinctive or learnt, conspicuous or perceptive. They are predictors of the worth of each TMT member in carrying out their tasks of managing their organizations [22]. Previous scholars have grouped top management team characteristics into three categories namely, demographic characteristics, cognitive characteristics and psychological characteristics [17]. Demographic characteristics are the observable or readily detectable features such as age, gender, education level, functional backgrounds and tenure. Psychological characteristics refer to subjective attributes such as personality traits and personal attitudes or beliefs such as self-esteem, self-efficacy, locus of control, emotional stability, task specific self-efficacy, optimism and resilience. Cognitive characteristics are associated with the ability of the TMT members to learn, remember, problem-solve and pay attention as they carry out their tasks [18].

Strategic management scholars and practitioners have defined organizational performance differently depending on their areas of focus [29]. Javier [12] defined organizational performance in terms of economic, efficient and effective utilization of organizational resources that is closer to Daft [7] who postulated organizational performance to be the capacity of an organization to realize its objectives and attain its goals through utilizing its assets in a proficient and appropriate manner. Ricardo and Wade [38] on their contribution defined organizational performance as the capability of an organization to maximize on its strengths while overcoming its weakness as well as to neutralize its threats while taking advantage of opportunities in order to achieve its objectives and goals. Not matter how the strategic management scholars or practitioners have defined organizational performance, there is a consensus among them that superior organizational performance is the most sought after outcome by all organizations be they public, private, national or multi-national, profit or non-profit organizations [30].

Kenya like most other developing countries formed independent regulatory agencies after liberalization in the late 1980s and 1990s as a special category of state owned organizations with oversight role over particular sectors or sub-sectors. The independent regulatory agencies license operators, set prices where necessary, protect consumers, enforce compliance to licence conditions and market rules, enforce standards as well as codes of practice for their particular sectors or sub-sectors. The main aim of introducing 
the independent regulatory agencies was to spur growth and improve services to consumers or end-users of the services by attracting private sector investments while maintaining government role of being responsible for public service provision in those sectors or sub-sectors [29]. Currently there are twenty-three independent regulatory agencies in Kenya although there are plans to merge some of them to make them more efficient and effective [37]. The management of the independent regulatory agencies like other state owned organizations in Kenya are vested in their board of directors and their top management teams. The identification and selection of the board of directors and the top management teams with the requisite characteristics for each independent regulatory agency has been identified as an aspect that affects their organizational performance [30]. Previous studies on performance of state corporations in Kenya have identified that some top management teams are deficient of appropriate talents that can enable implementation of suitable strategic management practices that could steer their organizations to the desired sustained superior organizational performance. Some of the top management teams have also been associated with failure of their organizations to align themselves to their ever changing and demanding business environments [22]. Several other factors like; utilization of resources, poor identification of stakeholders and their needs, lack of sufficient resources, in appropriate organization structures and weak corporate governance structures have also been identified as major contributors to variations in the performance of the independent regulatory agencies in Kenya [33].

\section{Statement of the Problem}

Some previous researchers in strategic management have shown that $66 \%$ of organizational strategies are never executed [13], while others have revealed that $95 \%$ of staff have no knowledge of their organizations' strategies [15] and others that only $63 \%$ of commercial outcomes projected by organizations' strategies are realized [21]. Also previous studies have shown that $70 \%$ to $90 \%$ of organizations fail to realize the forecasted achievements of executing their strategic plans [16] and that the most rampant cause of failure in strategies is unsuccessful execution [39]. Other previous studies have also shown that staff skills, firm systems and processes, management style, organizational culture and structure while aligned to organizational activities have a significant positive effect on strategy execution that in the end yield enhanced organizational performance [20].

Since the adoption of strategic management as a way of improving performance of organizations in the public sector in Kenya, most ministries, departments and agencies (MDAs) have continued to invest huge sums of money to improve their strategic planning. This is sometimes done through hiring of very good consultants to assist the organizations come up with excellent strategic plans but no commensurate investments and attention has been given to the strategy execution stage [26]. According to Springer [40], while strategies are most often developed by the board and stakeholders with great thought and care, implementation is often left to chance as the TMTs feel more comfortable with planning than implementation and they most often feel strategy implementation is best left to lower cadre staff and that it is not their responsibility. The fact that a wellarticulated strategy is the first critical ingredient of the implementation process does not necessarily lead to the desired strategic outcomes. The strategy formulation stage should be followed by the design of an appropriate organizational structure, establishing operating-level objectives, the design of operating structures and, finally, the creation of proper incentives and control mechanisms that support the strategy execution for the organizations to realize their primary goals of superior organizational performance [29].

Previous research findings have stated that TMT characteristics like level of managerial skills and knowledge of market information are not directly related to organizational performance but are related to organizational performance through appropriate strategic management practices [9]. According to Penrose [35], resources alone are not sufficient as inputs for organizational processes. It is rather the way that the resources are utilized that yield the desired superior organizational performance. Edelman, Brush and Manolova [10] also stated that it is more beneficial to organizations towards achieving their projected outcomes when resources like TMT capabilities are in line with organizational strategies.

\section{Literature Review}

\subsection{Theoretical Review}

Interest among strategic management scholars and practitioners in strategy execution has grown in recent years as business operating environments have become more dynamic and uncertain with time. It has been argued that consistent execution of strategy by top management teams is one of the top ten challenges facing most organizations. Most scholars and practitioners in strategic management have also agreed that TMTs in any organization play critical roles in strategy execution as they are the primary holders of the strategy execution process [26]. Top management teams have been identified as major contributors of ideas, act as links between various organizational levels and are performance role models in strategy execution process. Most current researches in strategic management have disagreed with previous postulations that limited the contribution of TMTs to the strategy formulation stage. This crop of scholars has argued that the greatest set of factors that affect strategy execution are resource allocation, technology deployment, operationalization of the organizational structure and organizational culture, all which require TMT's direct involvement [29].

McKinsey's 7S model is one of the diagrammatic representations commonly used by strategic management 
scholars to portray the key elements involved in strategy execution [14]. The model (Figure 1) shows the interconnections between the seven elements namely, strategy, structure, systems, staff, skills, style, and shared values that are believed to be core elements in effective strategy execution. The model depicts the array of the seven elements that form the organization's capability for executing their premeditated strategies. The $7 \mathrm{~S}$ model magnifies the principal role of organization's resources and capabilities in realizing their strategies. However other strategic management scholars have criticized the $7 \mathrm{~S}$ model that it ignores other factors that impinge on strategy execution like the external environment.

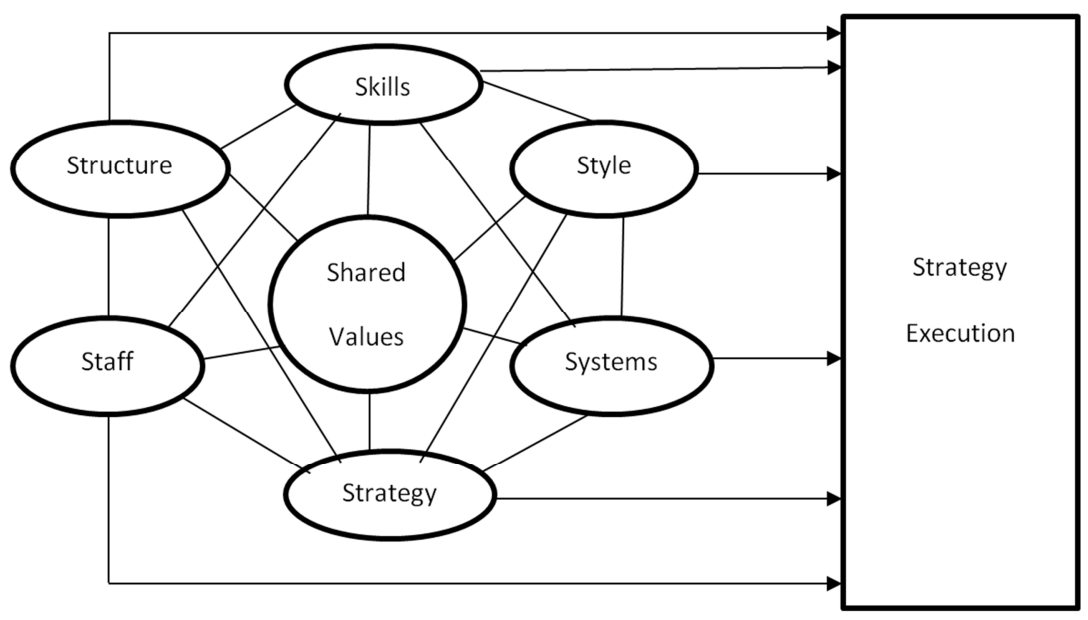

Source: Kaplan [2005]

Figure 1. McKinsey's 7 S Model of Strategy Execution.

The institutional paradigm of the theory of the firm asserts that organizational survival is determined by the extent to which the organization's internal arrangement and processes are aligned to pressures from its micro-environment and macro-environment. The effect of the legal environment and strategy execution on organizational performance is best explained by how the independent regulatory agencies identify opportunities and threats, how they chose the strategic decision and how they then execute them to attain superior organizational performance [26]. The contingency theory postulates that organizational performance is a consequence of the fit between several factors namely, structure, people, technology, strategy, and culture [19]. The contingency theory therefore underpinned the study of strategy execution by the independent regulatory agencies. According to the postulations of contingency theory, there is no best way to organize a corporation, to lead a company, or to make and execute decisions. The optimal course of actions in strategic leadership of organizations is dependent upon the internal and external situations [29].

\subsection{Conceptual and Empirical Review}

Pearce and Robinson (2011) expounded that to successfully handle all factors that influence growth and performance of an organization, the TMT must deploy strategies that propel the organization to sustained competitive advantage by capitalizing on the prospects in the business environmental and competitive demands. The TMT's actions must involve balancing the various interests of the organization's stakeholders that sometimes may be very divergent. The TMT must do this by projecting and setting various performance targets for their departments or divisions that feed into the organizational performance. It is against this background that the current study purposed to investigate the mediating influence of strategy execution on the relationship between TMT characteristics and organizational performance of independent regulatory agencies in Kenya.

Other previous studies have shown that aligning core organizational characteristics like staff skills, systems and processes, management styles, organizational culture and structure to strategies being implemented significantly influence strategy execution and results into superior organizational performance [40]. It has also been established that splitting the strategies being implemented by an organization into measurable activities outlined in work plans with timelines, allocating budgets to the activities and assigning responsibilities with reward for achievement of the set targets and penalties otherwise, also enhances strategy execution and is a stimulus for superior, organizational performance $[1,32,4]$.

Some of the previous studies have operationalized strategy execution in terms of leadership, resources, skills, communication, culture, systems and structure [26]. The current study categorized TMT characteristics into three subvariables namely, TMT demographics, TMT psychological and TMT cognitive characteristics. The study operationalized TMT demographic characteristics in terms of age, education, functional background, tenure [5] and gender representation [8]. The study conceptualized TMT psychological characteristics in terms of the following attributes; selfesteem, general self-efficacy, optimism, emotional stability, task specific self-efficacy, resilience and locus of control 
[18]. TMT cognitive characteristics was operationalized in terms of problem solving, attention, memory and learning [3]. Lastly, organizational performance was conceptualized in the study using the following attributes; effectiveness, efficiency, relevance and financial viability [25]. From the reviewed literature, the study thus hypothesized a relationship on the effect of strategy execution on the relationship between TMT characteristics and organizational performance as depicted in conceptual model below (Figure 2) where TMT characteristics is the independent variable, organizational performance is the dependent variable while strategy execution is the mediating variable.

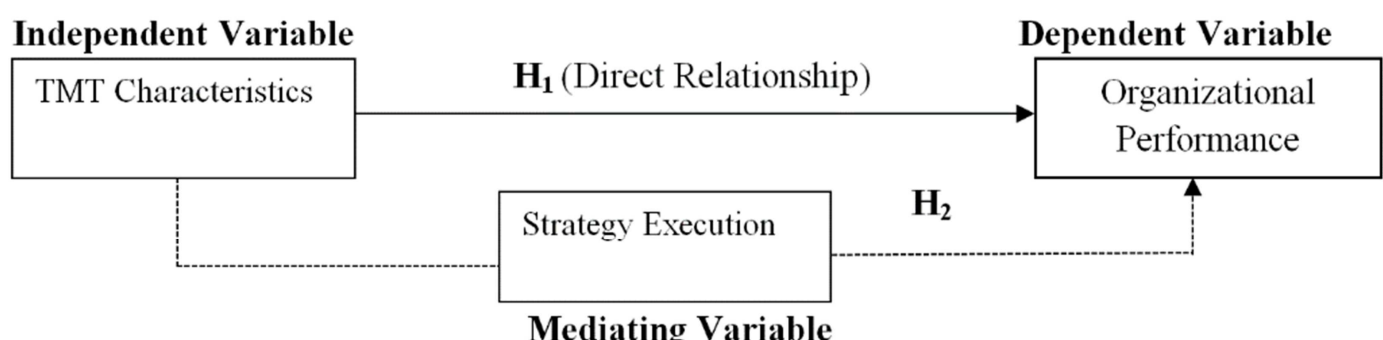

Mediating Variable

Figure 2. Conceptual Framework.

Based on the logic presented in the conceptual framework, the authors proposed that strategy execution would mediate the effect of TMT characteristics on organizational performance of independent regulatory organizations in the public sector in Kenya. Specifically, the study proposed that;

Hypothesis $\mathrm{H}_{1}$ : TMT characteristics has a significant effect on organizational performance of the independent regulatory agencies in Kenya.

Hypothesis $\mathrm{H}_{2}$ : Strategy execution has a significant mediating effect on the relationship between Top management team characteristics and organizational performance of the independent regulatory agencies in Kenya.

\section{Research Methodology}

The study objective was to look at what causes the particular relationships and what are the effects of these relationships hence it adopted positivism philosophy that favors where considerable amount of quantitative data is gathered for analysis [23]. Positivist philosophy was also considered suitable for the study as the researchers were independent of the phenomena under investigations and the properties of the occurrences were objectively measured [24]. As the study data was collected from the 232 TMTs spread across the twenty-three independent regulatory agencies at one point in time for analysis, cross-sectional survey research design was utilized. This is because cross-sectional survey research design favours where the desired data for each variable in the study can be collected from the entire population or a section of it to help test the research hypotheses [31]. In addition, other researchers like Mkalama [22], Muchemi [23], Ongeti [33] and Kasomi [17] while trying to test hypotheses and draw conclusions in similar studies successfully used cross-sectional survey research design.

The study context was the independent regulatory agencies in Kenya. According to the presidential task force on parastatal reforms (PTPR) of 2013, Kenya had one hundred and seventy-eight state corporations spread across eighteen government ministries as at 30th June 2013, out of which twenty three were independent regulatory agencies [31]. The unit of analysis for this study was the twenty-three independent regulatory agencies while the unit of observation was two hundred and thirty two TMTs spread across the twenty-three independent regulatory agencies in Kenya. The researchers used a census of all the 232 TMTs from all the independent regulatory agencies as each TMT was considered to have unique information relating to how strategy execution affected the relationship between TMT characteristics and organizational performance of their independent regulatory agencies [30].

Primary data was collected using a structured questionnaire comprising of closed ended questions. The questionnaire was developed in line with the research objectives and hypotheses [29]. Data on the variables were measured using a five point Likert Scale ranging from "not at all" (1) to "to a very large extent" (5). The positive responses were validated, edited for completeness and consistency upon receipt in order to prepare them for statistical analysis. Descriptive and inferential statistics were then used to analyze the prepared data [31]. Diagnostic tests of normality, multi-collinearity and homoscedasticity were carried out on the study data to confirmed that there were no violation of the assumptions of linear regression analysis that could result in biased estimates [6]. The test for the mediation effect adopted the causal four steps approach postulated by Baron and Kelly [2].

Step 1: The influence of TMT characteristics on Organizational Performance

The first model in the mediation was deployed to investigate the combined effect of the TMT characteristics on organizational performance.

Organizational Performance $=\beta_{10}+\beta_{11}$ TMT Characteristics $+\varepsilon$ (1)

Step 2: Effect of TMT characteristics on Strategy Execution

The second model was deployed to investigate the influence of TMT characteristics on strategy execution 
Strategy Execution $=\beta_{20}+\beta_{21}$ TMT Characteristics $+\varepsilon$.

Step 3: Effect of Strategy Execution on Organizational Performance

The third model was deployed to test the influence of strategy execution on organizational performance

Organizational Performance $=\beta_{30}+\beta_{31}$ Strategy Execution $+\varepsilon$.

Step 4: The combined influence of TMT characteristics and Strategy Execution on Organizational Performance

The fourth model was deployed to investigate the combined influence of TMT characteristics and strategy execution on organizational performance

Org. Performance $=\beta 40+\beta 41$ TMT characteristics $+\beta 42$ strat egy execution $+\varepsilon$

Where; $\beta$ ii $=$ Beta coefficient

\section{$\varepsilon=$ Error term}

The inferential statistics included regression model summary, ANOVA and regression coefficients of the independent variables. The hypotheses were tested at 0.05 significance level $(\alpha=0.05)$. Where the calculated $p$ value was less than 0.05 , the model was proven as statistically significant and the study failed to reject the null hypothesis but where the calculated $\mathrm{p}$ value was greater than 0.05 , the model was proven as statistically insignificant and the study rejected the null hypothesis.

\section{Research Findings}

\subsection{Respondents Characteristics}

Out of the 232 questionnaires distributed to the target respondents, 166 positively responded representing an overall response rate of $71.6 \%$. The positive respondents were from 19 independent regulatory agencies out of the targeted 23, representing $82.6 \%$ involvement of the independent regulatory agencies in Kenya. Similar previous studies conducted in the Kenyan context by Muchemi [23] and Muraga [25] had comparable response rates of $72.5 \%$ and $72.1 \%$ respectively. According to Mugenda and Mugenda [24]; 50\% response rate is considered adequate, $60 \%$ good and above $70 \%$ very good. The current study response rate was therefore established to be very good and appropriate. According Oketch, Kilika and Kinyua [29] very good response rates yield results that can be better inferred to a population. The respondent's characteristics are as shown in table 1 .

According to the statistics in table 1, majority of the respondents were heads of departments at $50.6 \%$ followed by directors/general managers at $27.1 \%$, heads of sections at $14.5 \%$, CEOs at $6.0 \%$, others at $1.2 \%$ and lastly deputy heads of departments at $0.6 \%$. These findings therefore confirmed that all of the respondents were CEOs and their direct reports as the top management teams were conceptualized in the study. The summarized statistics further show that the respondents were not fairly distributed across gender. There were more male respondents at $69.2 \%$ than female respondents at $30.8 \%$. For age distribution of the respondents, majority were in the age bracket of 46-50 at $39.2 \%$ followed by $41-45$ at $28.3 \%, 51-55$ at $20.5 \%, 36-40$ at $5.4 \%$, a tie of $31-35$ and above 55 at $3 \%$, and lastly 30 and below at $0.6 \%$. Concerning the highest level of education, majority of the respondents had master's degrees at $79 \%$, followed by bachelor's degrees at $11.4 \%$ and $\mathrm{Ph}$. D. at $9.6 \%$. On the functional area of the respondents, support functions with many departments had majority of the respondents at $60.8 \%$ while technical departments despite having few departments had $39.2 \%$.

Table 1. Respondents' Characteristics.

\begin{tabular}{|c|c|c|}
\hline Category & Number & Percentage \\
\hline \multicolumn{3}{|l|}{ Designation } \\
\hline CEO & 10 & 6.0 \\
\hline Director/GM & 45 & 27.1 \\
\hline Head of Department & 84 & 50.6 \\
\hline Deputy Head of Department & 1 & 0.6 \\
\hline Head of Section & 24 & 14.5 \\
\hline Others & 2 & 1.2 \\
\hline Total & 166 & 100 \\
\hline \multicolumn{3}{|l|}{ Gender } \\
\hline Male & 115 & 69.2 \\
\hline Female & 51 & 30.8 \\
\hline Total & 116 & 100 \\
\hline \multicolumn{3}{|l|}{ Age } \\
\hline 30 and Below & 1 & 0.6 \\
\hline $31-35$ & 5 & 3.0 \\
\hline $36-40$ & 9 & 5.4 \\
\hline $41-45$ & 47 & 28.3 \\
\hline $46-50$ & 65 & 39.2 \\
\hline $51-55$ & 34 & 20.5 \\
\hline Above 55 & 5 & 3.0 \\
\hline Total & 116 & 100 \\
\hline \multicolumn{3}{|l|}{ Education } \\
\hline Bachelors & 19 & 11.4 \\
\hline Masters & 131 & 79.0 \\
\hline $\mathrm{PhD}$ & 16 & 9.6 \\
\hline Total & 166 & 100 \\
\hline \multicolumn{3}{|l|}{ Tenure } \\
\hline $0-5$ & 82 & 49.4 \\
\hline $6-10$ & 66 & 39.8 \\
\hline $11-15$ & 14 & 8.4 \\
\hline $16-20$ & 1 & 0.6 \\
\hline Over 20 & 3 & 1.8 \\
\hline Total & 166 & 100 \\
\hline \multicolumn{3}{|l|}{ Functional Area } \\
\hline Support & 101 & 60.8 \\
\hline Technical & 65 & 39.2 \\
\hline Total & 166 & 100.0 \\
\hline
\end{tabular}

\subsection{Descriptive Statistics of the Study Variables}

Table 2 below depicts the descriptive statistics of the study variables comprising of the number of items used to measure the variables, Cronbach's alpha $(\alpha)$, aggregate mean score and aggregate standard deviation. 
Table 2. Descriptive Statistics of the Study Variables.

\begin{tabular}{lllll}
\hline Variable & No. of Items & $(\boldsymbol{\alpha})$ Score & Aggregate Mean Score & Aggregate Score Std Dev. \\
\hline TMT Demographic Characteristics & 16 & 0.859 & 3.684 & 0.867 \\
TMT Cognitive Characteristics & 9 & 0.944 & 4.570 & 0.430 \\
TMT Psychological Characteristics & 24 & 0.867 & 4.175 & 0.745 \\
Strategy Execution & 22 & 0.894 & 3.799 & 0.851 \\
Organizational Performance & 28 & 0.949 & 4.190 & 0.787 \\
\hline
\end{tabular}

The descriptive statistics presented in table 2 above show that all the variables had Cronbach's alpha values above the adopted study cut-off value of 0.7 at 0.859 for demographic characteristics, 0.867 for psychological characteristics, 0.944 for cognitive characteristics, 0.894 for strategy execution and 0.949 for organizational performance thus the research instrument passed internally consistency test. The overall aggregate mean scores were 3.684, 4.570, 4,175, 3.799 and 4.190 for demographic characteristics, cognitive characteristics, psychological characteristics, strategy execution and organizational performance respectively. These statics indicated that the respondents on average agreed to a moderate extent that the attributes of the demographic characteristics applied to their independent regulatory agencies while the standard deviation of 0.867 indicated that there were considerable variations within and among the state regulatory agencies. For psychological characteristics, the above statistics indicated that on average the respondents agreed largely with the attributes as pertains to their job performance in their current roles while the standard deviation of 0.745 indicated that the responses for psychological characteristics were more clustered around the mean scores than were the scores for demographic characteristics. For cognitive characteristics, the above statistics indicated that on average the respondents agreed largely with the attributes under cognitive characteristics as pertains to their job performance in their current roles. The standard deviation of 0.430 indicated that the responses for cognitive characteristics were more clustered around the mean scores than were the scores for both demographic characteristics and psychological characteristics. For strategy execution the statistics above indicated that the respondents on average agreed to a moderate extent that the attributes of strategy execution applied to their independent regulatory agencies while the standard deviation of 0.851 indicated that there were considerable variations within and among the independent regulatory agencies. Lastly, for organizational performance the above statistics indicated that the respondents agreed largely that the attributes of organizational performance applied to their independent regulatory agencies while the standard deviation of 0.877 indicated that there were considerable variations within and among the independent regulatory agencies.

\subsection{Test of Hypotheses}

The test of the research hypotheses was conducted in stages. First, the study tested the direct effect of TMT characteristics on organizational performance of the independent regulatory agencies. In order to test the hypotheses, a composite index of the various components of TMT characteristics was computed using the formula proposed by Kilika [43] based on the harmonic mean.

\subsubsection{Test of Hypothesis One}

This hypothesis sought to understand whether there is any statistically significant effect of the combined effect of TMT characteristics on the performance of the state regulatory agencies in Kenya. The regression analysis output is as summarized in in table 3.

Table 3. Regression of Organizational Performance on TMT Characteristics.

\begin{tabular}{|c|c|c|c|c|c|c|}
\hline \multicolumn{7}{|c|}{ Model Summary } \\
\hline \multirow{2}{*}{$\frac{\text { Model }}{1}$} & \multirow{2}{*}{$\begin{array}{l}\mathbf{R} \\
.556^{\mathrm{a}}\end{array}$} & \multirow{2}{*}{$\begin{array}{l}\text { R Square } \\
.309\end{array}$} & \multirow{2}{*}{$\begin{array}{l}\text { Adjusted R Square } \\
.305\end{array}$} & Std. Error of the Estimate & \multicolumn{2}{|c|}{ Durbin-Watson } \\
\hline & & & & .37618 & 2.049 & \\
\hline \multicolumn{7}{|c|}{ ANOVA } \\
\hline \multirow[t]{2}{*}{ Model } & & Sum of Squares & $\mathrm{df}$ & Mean Square & $\mathrm{F}$ & Sig. \\
\hline & Regression & 10.378 & 1 & 10.378 & 73.335 & $.000^{\mathrm{b}}$ \\
\hline \multirow[t]{2}{*}{1} & Residual & 23.208 & 164 & .142 & & \\
\hline & Total & 33.586 & 165 & & & \\
\hline \multicolumn{7}{|c|}{ Coefficients } \\
\hline \multicolumn{2}{|c|}{ Model } & \multicolumn{2}{|c|}{ Unstandardized Coefficients } & $\begin{array}{l}\text { Standardized Coefficients } \\
\text { Beta }\end{array}$ & $\mathrm{t}$ & Sig. \\
\hline & (Constant) & 1.030 & .361 & & 2.853 & .005 \\
\hline 1 & Combined TMT Characteristics & .763 & .089 & .556 & 8.564 & .000 \\
\hline
\end{tabular}

The results indicate that TMT characteristics explain $30.5 \%$ of the variation in organizational performance of the independent regulatory agencies in Kenya while the remaining $69.5 \%$ is attributable to other factors not included in the empirical model. The F statistic of 73.335 with a pvalue of 0.000 indicates that the regression model is significant in predicting this relationship. The summarized statistics in table 3 further show that the beta coefficient for the constant $\left(\beta_{0}\right)$ is 1.030 with a t statistics of 2.853 and a $p$ value of 0.005 while the standardized beta coefficient for the combined TMT characteristics $\left(\beta_{1}\right)$ is 0.556 with t statistics of 8.564 and $p$-value of 0.000 . Since the p-value is less than 
the significance level of 0.05 , combined TMT characteristics was judged a significant predictor of organizational performance. The $\beta_{0}$ of 1.030 implies that with the combined TMT characteristics held constant, organizational performance would be at 1.030 while $\beta_{1}$ of 0.556 indicates that if all other factors are constant, a unit change in the Top management characteristics would result to 0.556 change in organizational performance. Hypothesis one was therefore supported and the study concluded that TMT characteristics has a significant statistical effect on organizational performance of the independent regulatory agencies in
Kenya.

\subsubsection{Test of Hypothesis Two}

This hypothesis sought to understand whether there was any statistically significant mediating effect of strategy execution on the relationship between TMT characteristics and organizational performance of the independent regulatory agencies in Kenya. The mediating effect was tested using the four steps model proposed by Baron and Kenny (1986). The results from the four steps are summarized in table 4.

Table 4. Summary of Regression Results for the Mediating Effect.

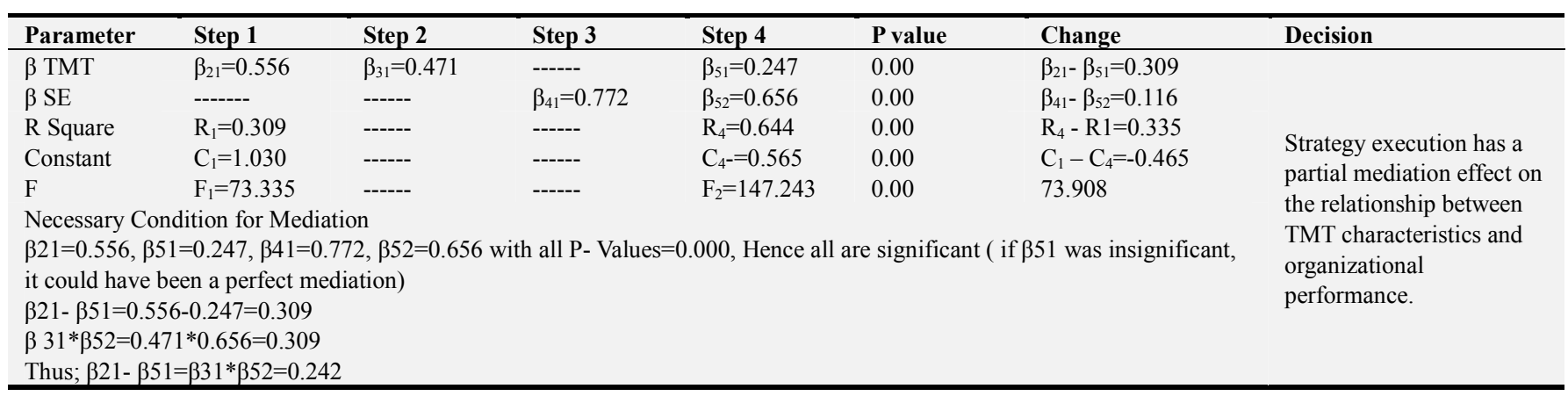

In order to understand whether there is a mediating effect of strategy execution on the existing relationship between TMT characteristics and organizational performance, the study relied on the criteria suggested by MacKinnon, Fairchild and Fritz [42]. The criteria states that if both the direct and the mediated relationships are significant, then there is evidence of a mediation. The criteria further states that, "if the treatment coefficient is zero when the mediator is included in the model then the relationship is entirely mediated by the mediating variable but if the absolute size of the direct effect between the independent variable and the dependent variable is reduced after controlling for the mediator then mediation effect is said to be partial". From the summary of regression results for the mediating effect presented in table 4, it can be seen that when TMT characteristics was regressed against organizational performance, the strength of the relationship was found to be a moderate strong positive one with the coefficient of correlation $\mathrm{R}=0.556$ with $\mathrm{R}$ Square $\left(\mathrm{R}^{2}\right)=0.309$ and beta coefficient $=0.556$ at $p$-value $=0.00$. When strategy execution was introduced the beta coefficient of TMT characteristics reduced by 0.309 units to 0.247 while the $R$ Square $\left(R^{2}\right)$ increased by 0.335 to 0.644 indicating a stronger explanatory power of TMT characteristics when strategy execution is present. Thus based on the mediation rule, the results of the test as to whether strategy execution has a mediating effect on the relationship between TMT characteristics and organization performance show that there is evidence of a partial mediation. The study therefore supported hypothesis two and concluded that strategy execution has a partial mediating effect on the relationship between TMT characteristics and organizational performance of independent regulatory agencies in Kenya. In view of these findings, the study observes that the strength of the relationship between TMT characteristics and organizational performance is dependent on the level of strategy execution exercised by the TMT members in their independent regulatory agencies.

\section{Discussion of Findings}

To explain the study findings, the researchers relied on the descriptive statistics, results from previous researchers and the contingency theory. The findings on the study hypotheses indicated that strategy execution has a partial mediation effect on the relationship between TMT characteristics and organizational performance. The study findings are consistent with other previous research findings that TMT characteristics like level of TMT skills and knowledge of market information are not necessarily directly related with organizational performance but are related with organizational performance through the use of appropriate strategic management practices [9]. The findings are also consistent with the findings by Penrose [35] that explained that resources are not the only necessary elements needed for superior organizational performance but that it is rather the way that the resources are utilized. Also according to Edelman, Brush and Manolova [10], it is further beneficial for organizations when resources like TMT characteristics such as capabilities are in line with organizational strategies. The descriptive statistics of strategy execution show that the sub-variables leadership, communications and culture had aggregate mean scores of $4.01,4.01$ and 4.40 respectively. This means that the respondents agreed to a large extend that the attributes measured in the study under the three sub-variables applied 
to their independent regulatory agencies. On the other hand, the sub-variables resources, systems, skills and structure had aggregate mean scores of $3.48,3.88,3.50$ and 3.16 respectively. This means that the respondents agreed to a moderate extent that the attributes measured in the study under the four sub-variables applied to their independent regulatory agencies. These findings could be explained by the fact that the sub-variables leadership, culture and communications are linked to strategic decision-making process while resources, systems, skills and structure enable and facilitate the execution of the strategic decisions made by the TMTs of the independent regulatory agencies.

The findings of the current study also support the postulates of the contingency theory that organizational performance is a consequence of the fit between several factors namely; leadership, people, structure, technology, strategy, and culture. The contingency theory therefore supports the relationship between top management team characteristics, strategy execution and organizational performance. It is clear from the contingency theory that organizations achieve success or superior organizational performance through alignment of leadership, people, structure, technology, strategy, and culture to the reasons for existence of the organizations. It is also evident that the top management teams must possess some attributes or characteristics that empower them to make good strategic decisions that are aligned to their organizations' prevailing business environments. The top management teams by putting these decisions into action results into superior organizational performance thus justifying the mediating role of strategy execution in the relationship between top management team characteristics and organizational performance.

\section{Contribution of the Study}

The findings of the current study fill the gap identified in the empirical literature review that in investigating the influence of TMT characteristics on organizational performance, it is important to include other variable that affect the relationship. Because TMTs are responsible for making strategic decisions for their organizations and implementing them to achieve the desired organizational outcomes, strategy execution is therefore one such variable that affects the relationship between TMT characteristics and organizational performance. The established mediating relationship therefore adds knowledge to strategic management research. The study findings also support the assertions of the contingency theory, that organizational performance is a consequence of the fit between several factors namely; leadership, people, structure, technology, strategy, and culture. Lastly, the findings offer evidence that strategic thinking is imperative for the public sector as well because their operating environments are becoming just as dynamic as for the competitive business environments.

\section{Conclusions and Recommendations}

From the findings of the study reported, the research makes two conclusions. First that, the respondents on average agreed to a moderate extent that the attributes of strategy execution applied to their independent regulatory agencies. And that the finding could be explained by the fact that the sub-variables leadership, culture and communications are mostly linked to strategic decision making process while resources, systems, skills and structure enable and facilitate the execution of the strategic decisions made by the TMTs of the organizations. Secondly, that strategy execution has a partial mediating effect on the relationship between top management team characteristics and performance of the independent regulatory agencies in Kenya.

The study likewise makes two recommendations. First, the study recommends that independent regulatory agencies need to develop a reward and recognition system for their TMTs and staff who excel in strategy execution so that they can be motivated. This is because it is through strategy execution that the independent regulatory agencies can deliver on their mandates and improve services to the citizens. Rewards provides an opportunity for the TMTs and staff to compete amongst themselves that would result in quality, productivity, efficiency and effectiveness in service delivery. Second, that the independent regulatory agencies should receive stable funding mechanism and not to rely on the parent ministries or exchequer support for them to be financially independent in executing their mandates.

\section{References}

[1] Alexander, L. D. (1985). Successfully Implementing Strategic Decisions. Long Range Planning, 18: 91-97.

[2] Baron, R. M., \& Kenny, D. A. (1986). The ModeratorMediator Variable distinction in Social Psychological Research: Conceptual, Strategic, and Statistical Considerations. Journal of Personality and Social Psychology, 51: $1173-1182$.

[3] Bouquet, C., Morrison, A. \& Birkinshaw, J. (2003). Determinants and Performance Implications of Global Mindset: An Attention-Based Perspective. Ivey Business School University of Western Ontario. London, ON Canada N6A-3K7.

[4] Buul, M. V. (2010). Successful Strategy Implementation: A Job for the Internal Auditor. Executive Master of International Auditing, Amsterdam Business School, University of Amsterdam.

[5] Carpenter, M. A. (2002). The Implications of Strategy and Social Context for the Relationship between Top Management Team Heterogeneity and Firm Performance. Strategic Management Journal, 23: 275-284.

[6] Chatterjee, S. \& Hadi, A. S. (2012). Regression Analysis by Example $\left(5^{\text {th }}\right.$ Ed.). John Wiley \& Sons: Hoboken, New Jersey.

[7] Daft, R. L. (2000). Organization Theory and Design, (7th Ed.) South-Western College Publishing, Thomson Learning. U.S.A. 
[8] Dezso, C. L. \& Ross D. G. (2012). Does Female Representation in Top Management Teams Improve Firm Performance? A Panel Data Investigation. Strategic Management Journal 33: 1072-1089.

[9] Dominic, T. \& Theuvsen, L. (2015). Agribusiness Firm Resources and Performance: The Mediating Role of Strategic Management Practices. GlobalFood Discussion Papers (24).

[10] Edelman, L. F., Brush, C. G., \& Manolova, T. (2005). Coalignment in the resource-performance relationship: strategy as mediator. Journal of Business Venturing, 20 (3): 359-383.

[11] Ibrahim, M., Sulaiman, M., Kahtani, A. A. \& Abu-Jarad, I. (2012). The Relationship between Strategy Implementation and Performance of Manufacturing Firms in Indonesia: The Role of Formality Structure as a Moderator. World Applied Sciences Journal, 20 (7): 955-964, ISSN 1818-4952.

[12] Javier (2002). A review paper on Organizational Culture and Organizational Performance. International. Journal of Business and Social Science, 1 (3): 52-76.

[13] Johnson, L. K (2004). Execute your strategy without killing it. Harvard Management Update: 3-5.

[14] Kaplan, R. S. (2005). How the balanced scorecard complements the McKinsey 7-S model. Strategy \& Leadership, 33 (3): 41-46.

[15] Kaplan, R. S. \& Norton, D. P. (2005). Creating the office of strategy management. Harvard Business Review, 83 (10): 72 80 .

[16] Kaplan, R. S. \& Norton, D. P. (2006). Strategy Maps: Converting Intangible Assets into Tangible Outcomes, Boston: Harvard Business School Press.

[17] Kasomi. F. M., (2015). Diversity in Top Management Teams, Strategic Choice, Top Manager's Compensation Schemes and Performance of Kenyan State Corporations. (Unpublished $\mathrm{PhD}$ Thesis). University of Nairobi, Department of Business Administration, School of Business, Nairobi.

[18] Kinuu, D. (2014). Top Management Team Psychological Characteristics, Institutional Environment, Team Processes and Performance of Companies listed in Nairobi Securities Exchange. (Unpublished PhD Thesis). University of Nairobi, Department of Business Administration, School of Business, Nairobi.

[19] Lawrence, P., \& Lorsch, J. (1977). Organization and Environment: Managing Differentiation and Integration. Homewood, IL: Irwin.

[20] Letting, N, Aosa, E., \& Machuki V. (2012). Board diversity and Performance Companies listed in Nairobi Stock Exchange. International Journal of Humanities and Social Sciences, 2 (11): 172-182.

[21] Mankins, M. C., \& Steele R. (2005). Turning Great Strategy into Great Performance. Harvard Business Review, JulyAugust: 65-71.

[22] Mkalama. R. N., (2014): Top Management Team Demographics, Strategic Decisions, Macro-Environment and Performance of Kenyan State Corporations (PhD Thesis). University of Nairobi, Department of Business Administration, School of Business, Nairobi.

[23] Muchemi, W. A., (2013). Top Management Team Diversity and Performance of Commercial Banks in Kenya. (PhD Thesis). University of Nairobi, Department of Business Administration, School of Business, Nairobi.

[24] Mugenda, O. M. \& Mugenda, A. G. (2003). Research Methods: Quantitative and Qualitative Approaches. Nairobi: ACTS Press.

[25] Muraga, D. K. (2015). Strategic Human Resource Management Practices and Performance of Parastatals in Kenya. (Ph. D Thesis). Kenyatta University.

[26] Njoronge, J. K., (2015). Strategy Implementation, Performance Contracting, External Environment and Performance of Kenyan State Corporations. (PhD Thesis) University of Nairobi, Department of Business Administration, School of Business, Nairobi.

[27] Njoronge, J. K., Machuki, V. N., Ongeti, W. J., \& Kinuu, D. (2015). The Effect of Strategy Implementation on Performance of Kenya State Corporations. Prime Journal of Business Administration and Management (BAM) ISSN: 22511261. Vol. 5 (9): 1913-1922.

[28] Oketch, J. O., \& Kilika, J. M. (2017). Linking Top Management Team Characteristics and Strategy Execution with Firm Performance. A Review of Literature. The International Journal of Business and Management ISSN: 2321-8916. Vol. 5 (1): 74-81.

[29] Oketch, J. O., Kilika, J. M. \& Kinyua, G. M. (2020). The Moderating Role of the Legal Environment on the Relationship between TMT Characteristics and Organizational Performance in a Regulatory Setting in Kenya. Journal of Economics and Business Vol. 3 (1): 211-222.

[30] Oketch, J. O., Kilika, J. M., Kinyua G. M. (2020). Top Management Team Psychological Characteristics and Organizational Performance. Journal of Business and Economic Development. Vol. 5 (1), pp. 36-43. doi: 10.11648/j.jbed.20200501.15.

[31] Oketch, J. O., Kilika, J. M., Kinyua G. M. (2020). Top Management Team Cognitive Characteristics and Organizational Performance. IOSR Journal of Business and Management. Vol. 22 (2): 22-30.

[32] Okumus, F. (2003). A Framework to Implement Strategies in Organizations. Management Decision, 41 (9): 871-882.

[33] Ongeti, W. J., (2014). Organizational Resources, Corporate Governance Structures and Performance of Kenyan State Corporations. (PhD Thesis). University of Nairobi, Department of Business Administration, School of Business, Nairobi.

[34] Pearce, J. A., \& Robinson, R. B., (2011). Strategic Management: Formulation, Implementation and Control. McGraw HillIrwin, 1221 Avenue of the Americas, New York, NY 10020.

[35] Penrose, E. T. (2009). The Theory of the Growth of the Firm: With a New Introduction by Christos N. Pitelis (4th Edition). Oxford: Oxford University Press.

[36] Pride, W. M. \& Ferrell, O. C. (2003). Marketing: Concepts and Strategies (Vol. 1). Boston, MA: Houghton Miffin Company.

[37] PTPR, (2013). Report of the Presidential Taskforce on Parastatal Reforms. Retrievedatwww.apsea.or.ke/.../76-reportof-presidential-taskforce-on-parastatal-reforms. 
[38] Ricardo, R. and Wade, D. (2001). Corporate Performance Management: How to Build a Better Organization through Measurement driven Strategies alignment. Butterworth, Heinemann.

[39] Slater, S., Olson, E. \& Hult, G. (2010). Worried about strategy implementation? Don't overlook marketing's role. Business Horizons, 53: 469-479.

[40] Springer, C. G. (2005). Keys to Strategy Implementation. PA TIMES, 28 (9): 9.

[41] Waterman, R., Peters. T. \& Phillips, J. (1980). Structure is Not Organization. Business Horizons, 23 (3): 14-26.
[42] MacKinnon, D., Fairchild, A., \& Fritz, M. S. (2007). Mediation Analysis. Annual Review of Psychology, 58: 593614.

[43] Kilika, J. M., K’Obonyo, P. O., Ogutu, M., \& Munyoki, J. M. (2012). Toward understanding the Design of Human Resource Development Infrastructures for Knowledge Intensive Organizations: Empirical Evidence from Universities in Kenya. DBA Africa Management Review, 2 (2).

[44] Wit, D. R., \& Meyer, R., (2004). Strategy Process, Content, Context: An International Perspective. South-Western Cengage learning. UK. 